\title{
Cláudia Garcia
}

Arquiteta, doutora em Arquitetura e Urbanismo na área de estética e história da arte pela Universidade de Brasília, atualmente é professora adjunta na Faculdade de Arquitetura e Urbanismo Universidade de Brasilia.

\section{RESUMO}

Por meio de construção de um diálogo acadêmico esse artigo visa uma abordagem sobre a importância do desenho na práxis e na formação do arquiteto. Defendo a ideia do desenho nos termos proposto por Artigas, cujo fundamento recai sobre o reconhecimento do desenho como desígnio, aquele que engendra a dimensão estética. Nesses termos, o desenho antecipa um significado além da representação do objeto a ser construído, graças aos atributos plásticos que podem vir a lhe conferir um valor artístico. Resgatar o entendimento do desenho como desígnio constitui um caminho que identifica a praxis e a formação profissional na Arquitetura como praxis artística. Portanto, uma formação critica e libertária. Da análise da composição depreende-se uma análise estética capaz de motivar a sensibilidade do fruidor. O futuro desenho, do projeto, nasce de uma reflexão crítica e deve considerar as necessidades do presente e as raízes passadas, com vistas a construção de um futuro. $O$ objetivo é vislumbrar o compromisso da criação arquitetônica com o desenho, do ponto de vista da sua dimensão estética.

Palavras chave: desenho; projeto; estética.

\section{ABSTRACT}

Through the construction of an academic dialogue, this article aims at an approach on the importance of the drawing in the praxis and formation of the architect I defend the idea of the drawing in the terms proposed by Artigas, whose foundation recognizes of the drawing as "desígnio", that which engenders the aesthetic dimension. In these terms, of the drawing anticipates a meaning beyond the representation of the object to be built, due to the plastic attributes that may give it artistic value. To rescue the understanding of the drawing as design constitutes a path that identifies the praxis and professional formation in Architecture as artistic praxis. Therefore, a critical and libertarian formation. From the analysis of the composition we can see an aesthetic analysis capable of motivating the sensitivity of the user. The drawing of the project is born of a critical reflection and must be to consider the needs of the present and the past, with a view to building a future. The objective is to glimpse the commitment of the architectonic creation with the drawing, from the point of view of its aesthetic dimension.

Keywords: drawing; desígnio; design; aesthetics. 
A consciência humana, com seu lado sensivel e seu lado racional, não tem sido convenientemente interpretada como um inteiro, mas como a soma de duas metades. Aos artistas, principalmente, compete conhecer esta dicotomia para ultrapassá-la com certeza, a semântica da palavra desenho tende a enniquecer nessa direção. Sentimos já as primeiras mudanças. 0 desenho não é a única linguagem para o artista E as linguagens são formas de comunicação ligadas estreitamente ao que exprimem. Da Vinci dizia: "Os olhos são a janela da alma". Nossa linguagem é essencialmente visual, de comunicação visual. A arte não é um símbolo, como supõem os filósofos da frustraç̃̃o. os símbolos são frases, on se quiserem, são versos que compõem o poema para os arquitetos da atualidade, é importante que se exprimam com símbolos novos. os novos símbolos são irmãos das novas técnicas, e fillhos dos velhos símbolos. como se viu, ninguém desenha pelo desenho.

Para construir igrejas há que têtlas à mente, em projeto. Darodiando Bluteau, agrada-me interpelar-vos, particularmente aos mais jovens, os que ingressam hoje em nossa Escola: que catedrais tendes no pensamento? Aqui aprendereis a construí-las duas vezes: aprendereis da nova técnica e ajudareis na criação de novos símbolos.

Uma sintese que só ela é criação. A "obra do homem com sua longa vida histórica é uma obra de arte" Sobre qualidade. Sobre quantidade. Que diga o poeta dos maiores de nossa língua, Fernando Dessoa: Quanto facas, supremamente faze. Mais vale, se a memória é quanto temos, Lembrar muito que pouco. E se o muito no pouco te é possível, Mais ampla liberdade de lembranca Te tornará teu dono. (Artigas, 1999) 
Parodiando Bluteau:

\section{- Que catedrais desenha em pensamento?}

\section{- Mas de que desenho tu falas?}

\section{- Falo do desenho como desígnio.}

No sentido de "chama divina", dita por Federico Zuccari, em princípios do século XVII, que definia o desenho como "forma expressa de todas as formas inteligiveis e sensiveis que dá luz ao intelecto e vida as atividades, ou seja, a chama divina" Falo do desenho interno que "é o conceito, e a ideia, que qualquer um forma para poder conhecer e operar. Esobre a origem divina do "conceito" este que se transmite da alma ao corpo". Ou ainda a chamada "proposta de espírito" apontada por Artigas.

\section{O disegno, que tem autoridade ampla, absoluta e geral para reger e governar esta república de signos, e este intelecto humano como lugar-tenente, imagem e semelhança de Deus [Dio] em nós, sela patente e privilégio com seu próprio nome DI-SEGN-O que, como se vê e se disse, outra coisa não denota que signo de imagem e semelhança divina na nossa alma, como reitor e governador e lugar-tenente, com a faculdade de avivar , alimentar e aumentar toda ciência e prática neste baixo intelecto, de prover e ministrar segundo convém a toda necessidade humana, como claro se compreende e vê" (ZUCCARO, 1607)}

Minha intenção é defender uma formação artística nas escolas de Arquitetura, com o que se resgata o papel fundamental do desenho na formação profissional. A formação do arquiteto e a do artista coincide; a técnica será tributária do intento artístico.

E quem sabe nos termos proposto por Alberto Giacometti, quando ele afirma que "de fato, apenas o desenho conta. É preciso agarrar-se única e exclusivamente ao desenho. Se dominamos um pouco o desenho, todo o resto seria possivel." Sendo o desenho o elemento que dá origem às primeiras sementes da obra de Arquitetura, como praxis humana, ele deve objetivar, como criação artística, a união das dimensões subjetivas e objetivas, individuais e coletivas, bem como conjugar a ideia de criação humana em sua totalidade.
Além de cumprir os objetivos de natureza prática à qual se destina, há que ter um significado na forma do desenho, que é o projeto. Nos termos proposto por Gorovitz (1994: 26), onde categoria da totalidade é entendida como um "conjunto das necessidades, prerrogativas e possibilidades humanas consideradas ou exercidas de forma integrada; quando o lado sensível e o lado racional da consciência se desenvolvem não fragmentados, ou seja, em condições de plenitude ou de adversidade."

- Mas como posso compreender esse sentido de totalidade, se a obra de arquitetura se destina a uma necessidade prática?

- Muitas vezes precisamos nos valer de alguns conceitos além daqueles que estamos familiarizados para nos ajudar a compreender alguns significados.

Busco o sentido da totalidade humana nos termos idealizados, inicialmente, pela filosofia clássica alemã, em Kant, Hegel e Marx, e que marcam a transição do pensamento metafísico para a concepção dialética. Subentende-se a significado de totalidade como a indissociabilidade das esferas do subjetivo e do objetivo. Sujeito e objeto são, na concepção dialética, antitéticos e complementares, interagindo num processo do qual a obra de arte emerge como uma das sínteses possíveis. Síntese que ao privilegiar, seja o universo sensorial, o racional ou o cognitivo, denuncia o equilíbrio, a tensão ou o conflito dessas capacitações do ser. (GOROVITZ: 2000)

- Quer dizer que o desenho pode traduzir, além da necessidade construtiva da obra em si, o sentido de criação artística?

- Sim. Lucio Costa pode nos ajudar a compreender o entendimento de totalidade quando define o que é arquitetura.

[...] antes de mais nada construção, mas, construção concebida com o propósito primordial de ordenar e organizar o espaço para determinada finalidade e visando a determinada intenção. E nesse processo fundamental de ordenar e expressar-se ela se revela igualmente arte plástica, porquanto nos inumeráveis problemas com que se defronta o arquiteto desde a germinação do projeto até a conclusão efetiva da obra, há sempre, para cada caso específico, certa margem final de opção 
entre os limites - máximo e mínimo determinados pelo cálculo, preconizados pela técnica, condicionados pelo meio, reclamados pela função ou impostos pelo programa, - cabendo então ao sentimento individual do arquiteto, no que ele tem de artista, portanto, escolher na escala dos valores contidos entre dois valores extremos, a forma plástica apropriada a cada pormenor em função da unidade última da obra idealizada. A intenção plástica que semelhante escolha subentende é precisamente o que distingue a Arquitetura da simples construção. (COSTA, 1995:246)

Lucio Costa (1980:5) traduz a seu modo o conceito de totalidade, dizendo que "o que caracteriza a obra de arte é precisamente esta eterna presença, na coisa, daquela carga de amor e de saber que, um dia, a configurou". Quando define Arquitetura, objetiva nessa mesma direção.

Um desenho de arquitetura como expressão do conhecimento sensível, pode significar uma obra de arte, implica em um reconhecimento que, além de cumprir os objetivos de natureza prática para os quais se volta, sua forma significa, e o significado dessa forma deve conter esse sentido de totalidade humana.

Gorovitz quando se apoia em Schiller, também nos ajuda a compreender esse significado ao afirmar que, do ponto de vista do "conhecimento sensível", as categorias conceituais tratadas pela estética permitem fundamentar o caráter disciplinar, viabilizando a possibilidade da transmissão do conhecimento, do diálogo peripatético em torno da experiência estética.

Veja esse trecho das "Cartas sobre a Educação estética do Homem", de Schiller:

Para o leitor não totalmente familiarizado com o significado preciso deste termo Estética, tão abusado pela ignorância, o que se segue poderá servir como explicação. Todas as coisas capazes de manifestação fenomênica podem ser consideradas sob quatro aspectos diferentes. Uma coisa pode se relacionar com os nossos sentidos (com o nosso ser e bem-estar): este é o seu caráter físico. Ou pode se relacionar com o nosso intelecto e nos proporcionar o conhecimento: este é o seu caráter lógico. Ou pode se relacionar com nossa vontade, e ser considerado como um objeto de escolha por um ser racional, este é o seu caráter moral. Ou

finalmente, pode se relacionar com a totalidade das nossas diferentes funções sem ser um objeto definido por nenhuma delas singularmente: e este é o seu caráter estético. (SCHILLER, apud GOROVITZ, 2000:5)

Desta forma, devemos olhar com cuidado a idealização dos projetos pedagógicos dos cursos de arquitetura. As diretrizes curriculares definem os caminhos para construção desses projetos e têm por objetivo estabelecer critérios gerais para que cada instituição desenhe seu curso. Esse projeto, que também é político, tem como finalidade estabelecer uma identidade educativa, formativa e distintiva, como elemento articulador das ações pedagógicas de um curso. Por isso, a discussão que trago aqui é oportuna. Surge uma questão fundamental: Qual a visão da formação do arquiteto no ensino do projeto articulada ao desenho como desígnio, ou seja, ao desenho vinculado à estética?

Mais uma vez inspirada em Lucio Costa, me arrisco a dizer que a melhor forma de prever é olhar para trás (COSTA, 1995). O tratado de Alberti não pereceu no tempo, se verificarmos que o oficio da Arquitetura, ainda, é reconhecer, além das necessidades de adequação da cidade e do homem às novas condições materiais, técnicas e econômicas de sua época, a dimensão artística, é ser capaz de consubstanciar o caráter utópico, os anseios de um viver melhor.

Embora, nosso modo de vida contemporâneo esteja fortemente pautado na era tecnológica, não há impedimento para, ainda, delinearmos um trajeto sedimentado nos princípios artísticos e, para isso, defendemos uma educação estética, na formação dos arquitetos, inspirada entre outros caminhos no tratado de Alberti. Para que o arquiteto é aquele que, com o ajuda da razão e de uma regra perfeita e precisa, possui a sabedoria de dividir as coisas com o seu espírito e com a sua inteligência e compõe com perfeição, no decurso do trabalho de construção, todos aqueles materiais que pelo movimento das massas e ajuste dos corpos, podem atender dignamente as necessidades do homem (ALBERTI, 2012).

É nessa direção que Lucio Costa define a Arquitetura e situa a praxis do arquiteto como um fazer artístico, ao tempo em que reconhece as dimensões sociais, econômicas, culturais, funcionais desse ofício reiterando, assim, o significado de totalidade, cujo desenho traduz essa possibilidade. 


\section{- Mas como posso compreender o significado de desenho como desígnio inserido nesse contexto de totalidade?}

- O ponto de partida é compreender o próprio significado da palavra. Desígnio é um substantivo masculino que tem por sinônimo as palavras intenção, projeto, plano ou propósito. Na mesma direção a palavra desenho pode ser traduzida por traçado, risco, projeto, plano e no sentido figurativo assume a condição de intento, propósito, desígnio. (DICIONÁRIO AURÉLIO)

Artigas, em 1967, em uma aula inaugural, no curso de arquitetura da FAU da Universidade de São Paulo (USP), apresentou seu dircuso intitulado "O desenho". Com base na origem da palavra "desenho", demonstrou aos futuros arquitetos o compromisso com seu oficio. Expos, historicamente, a eterna busca artística dentro da arquitetura e pautou seu discurso afirmando que "[...] o conflito entre a arte e a técnica prevalece ainda hoje. Ele desaparecerá na medida em que a arte for reconhecida como linguagem dos desígnios do homem". (ARTIGAS, 1999:71)

Exatamente nesse sentido que busco contextualizar o significado de desenho para e na arquitetura. Embora o discurso de Artigas situe a relação entre a arte e a Revolução Industrial, suas observações não perdem força frente à revolução tecnológica que vivemos hoje.

O fim do século XX e o início do século XXI foram marcados por um novo paradigma tecnológico, que se estrutura na revolução da tecnologia digital. 0 impacto desse progresso na sociedade atual pode ser comparado ao causado pela Revolução Industrial no séculoXIX.

A preocupação de Artigas pautava-se na substituição do homem pela máquina nas atividades de trabalho e, consequentemente, no processo de criação artística. Entretanto, a história mostra que isso não ocorreu, pois a garantia do fazer artístico está na capacidade criativa do homem, cujo entendimento reside no significado da arte. Apoiado e Clive Bell que define arte como "significantform", ele diz:

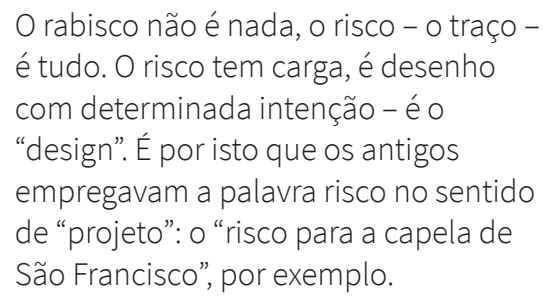

Trêmulo ou firme, esta carga é o que importa.

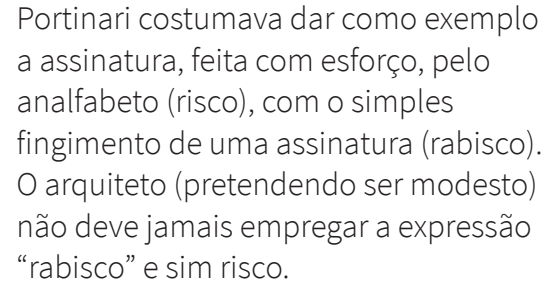

Risco é desenho não só quando quer compreender ou significar, mas "fazer", construir. (COSTA, 2007)

Em um sentido geral, podemos entender por arte "um conjunto de regras capazes de dirigir uma atividade humana qualquer". No entanto, Artigas atribui ao significado de arte a visão kantiana, quando afirma que arte é contemplação. Ora, a criação é humana, porque é "criação do indivíduo que a realiza." O artista não maneja a quantidade e sim, a qualidade. E a máquina, e segundo Artigas (1999:73), "é uma força de reproduzir coisas idênticas para os fins mais imediatos e primários. O homem, nestas condições, torna-se náufrago num mar de objetos desprovidos de qualquer outro valor que o utilitário. A arte não é útil, é contemplação [...]".

Para Kant há a distinção entre a arte mecânica da arte estética. A primeira é aquela que cumpre somente as operações necessárias para realizá-lo; a segunda éa que tem por fim imediato o sentimento do prazer e pode ser aprazível ou bela. É aprazível quando sua finalidade é fazer com que o prazer acompanhe as representações como simples sensações; é bela quando seu fim é conjugar o prazer às representações como formas de conhecimento. Em outros termos, a bela arte é uma espécie de representação cujo fim está em si mesmo e, portanto, proporciona prazer desinteressado; as artes aprazíveis visam somente a fruição. (ABBAGNANO, 2000)

Gorovitz, em suas aulas, nos dizia que as técnicas que interessam a estética são aquelas que utilizam as artes. Se os procedimentos intuitivos e espontâneos, que não relevam a técnica, têm lugar na arte, eles não são os únicos e os conhecimentos técnicos tem lugar não menor. Elas dão ao artística os meios de agir, e um domínio que evita a incerteza ou os fracassos práticos; elas permitem, portanto trazer o essencial do trabalho e da pesquisa sobre o aspecto propriamente da arte. Por outro lado, como os meios empregados contribuem ao efeito da obra idealizada, não levar em consideração os procedimentos técnicos podem empobrecer ou falsear o julgamento sobre a obra de arte. 


\section{- Mas como situar a Arquitetura nesses termos?}

- Boa pergunta. Há, na Arquitetura, condições inerentes que a situam além da bela arte: por um lado, por sua função de abrigo e organizadora do espaço (ordem de natureza prática); por outro lado, por seu caráter construtivo (ordem de natureza técnica). Voltamos a Artigas para melhor compreender.

Ele nos diz que não pode haver um divórcio entre arquitetura como técnica, que engendra um modo de construir, como função que se presta a uma atividade, e a arquitetura como linguagem do fazer artístico. Em seu discurso ele não toma partido contra a máquina ou contra a técnica, ao contrário e nos diz:

Não esperem de mim tomar partido contra a máquina ou contra a técnica. Muito ao contrário, julgo que, diante delas, os arquitetos e os artistas em geral viram ampliar-se o seu repertório formal, assim como se ampliaram seus meios de realização. Alinho-me entre os que estão convictos de que a máquina permite à arte uma função renovada na sociedade. É esta, aliás, a tese que pretendo experimentar aqui, aproveitando a oportunidade para tecer considerações em torno do desenho, linguagem da Arquitetura e da técnica. O "desenho" como palavra, segundo veremos, traz consigo um conteúdo semântico extraordinário. Este conteúdo equipara-se a um espelho, donde se reflete todo o lidar com a arte e a técnica no correr da história. É o método da linguística; do "neo-humanismo filológico e plástico, que simplesmente se inicia, mas que pode vir a ser uma das formas novas de reflexão moderna sobre as atividades superiores da sociedade. 0 conteúdo semântico da palavra desenho desvenda o que ela contém de trabalho humano acrisolado durante o nosso longo fazer histórico. (ARTIGAS, 1999:48)

O cerne da questão é reconhecer o desenho como instrumento de criação humana, como ideário, e que reúne em si, a possibilidade de união entre arte e técnica. Desta maneira, Artigas nos ajuda a compreender como a palavra desenho assume conteúdos semânticos diferentes, porém entrelaçados: desenho como representação1 e como intenção2, quando diz que em "nossa língua, a palavra aparece no fim do século XVI. Dom João Ill, em carta régia dirigida aos patriotas brasileiros que lutavam contra a invasão holandesa no Recife, assim se exprime, segundo Varnhagen: Para que haja forças bastantes no mar, com que impedir os desenhos do inimigo, tenho resoluto etc. Portanto, desenho designa: intenção; planos inimigos". (ARTIGAS, 1999:48)

Um século mais tarde, o Padre Bluteau registrou em seu vocabulário português e de latino: "Dezenhar: ou dezenha no pensamento. Formar huma ideia, idear. Formam in animo designare. Quais as igrejas que dezenhava no pensamento (Vida de São Xavier de Lucena)". Registra também o significado técnico. "Desenhar no papel". Formam in animo designatam lineis describere-delineare. "Que desenhasse a fortificação". (ARTIGAS, 1999:73)

A intenção se consubstancia e se objetiva numa ação. A citação de Bluteau lembrada por Artigas - Quais as igrejas que desenhava no pensamento? assume o sentido de desenho como um ideário, uma intenção. Para o homem, a ação de desenhar pode significar um caminho de realização, ou seja, de tornar real e presente uma ideia. O desenho traduz um pensamento, um propósito, um desígnio. É uma ação e uma atitude cujo objetivo é realizar algo particular. Portanto, transformar a partir de uma realidade fenomênica traduzida pela imaginação do homem.

A pergunta de Bluteau lembrada por Artigas me motiva e, acima de tudo, me estimula a trilhar a crença sobre o sentido de desenho como desígnio, tão fundamental no oficio do arquiteto e que renasce como ideário no mundo moderno. Recorremos mais uma vez a Artigas:

No Renascimento o desenho ganha cidadania. E se de um lado é risco, traçado, mediação para expressão de um plano a realizar, linguagem de uma técnica construtiva, de outro lado é desígnio, intenção, propósito, projeto humano no sentido de proposta do espírito. Um espírito que cria objetos novos e os introduz na vida real. 0 disegno do Renascimento, donde se originou a palavra para todas as outras línguas ligadas ao latim, como era de esperar, tem os dois conteúdos entrelaçados. Um significado e uma semântica, dinâmicos, que agitam a palavra pelo conflito que ela carreia consigo ao ser a expressão de uma linguagem para a técnica e de uma linguagem para a arte. (ARTIGAS, (1999: 73) 
Inspirada em Artigas, vamos considerar que, apesar de todas as possibilidades da era digital, não devemos perder de vista os significados essenciais do desenho e a sua relação com a dimensão estética.

Nesse sentido podemos relacionar o desenho à Arquitetura, ou seja, a seus atributos plásticos e às possibilidades técnicas de sua representação e expressão; consequentemente, aos rebatimentos da obra arquitetônica em si, para se ter a consciência de que o desenho, como concepção de uma ideia, faz parte de um processo no qual tudo se transforma. Esse é o sentido da arte: entender que é possível pensar pelo desenho, como instrumento da criatividade e, não, como ferramenta do projeto.

- Será que as escolas de arquitetura tem abandonado o entendimento do desenho (desígnio) no fazer arquitetônico?

- Se o objetivo recair apenas ao caráter de representar o objeto arquitetônico a ser construído, o mais próximo possível da realidade, em detrimento da chamada "proposta de espírito" apontada por Artigas, eu diria que sim.

Minha intenção é defender uma formação artística, e resgatar seu fundamental papel para formação profissional. A formação do arquiteto e a do artista coincide. A técnica será tributária do intento artístico.

Além dessas prerrogativas, também é necessário questionar sobre o não entendimento, ou talvez, sobre a falta de compreensão do sentido de desígnio, sobre a ausência de perspectiva, a perda da esperança ${ }^{3}$ e a impossibilidade atual de encarar a história como processo de transformação no qual se pode intervir. Com base nos argumentos que motivaram Artigas (1999:73) a dizer que "A Arquitetura moderna originouse das esperanças de transformação social do mundo frente à Revolução Russa", a arte pode ser entendida, também como propõe Artigas, como "[...] uma das formas concretas e necessárias da ação do homem na criação de uma natureza propriamente humana".

Na criação arquitetônica, o desenho invade o campo da imaginação ${ }^{4}$, especificamente da imaginação criadora, que traz as bases da transformação e que se refere à necessidade humana de criar um "mundo" ao qual todos possam ter acesso. A imaginação passa do sonho à realidade, traduzida pela criação artística. A Arquitetura é uma modalidade de manifestação artística, e o desenho é capaz não apenas de assinalar, mas de consubstanciá-la como arte.
- Fica uma dúvida, em que situação o desenho assume a condição de desígnio na arquitetura?

- Quando se apresenta como criação artística.

Recorremos, inicialmente, a Lúcio Costa: "Para o sentimento quando se toca; para a imaginação quando se solta; para a inteligência quando "bola" a coisa ou está diante dela e deseja penetrar-lhe o âmago e significar - o desenho como meio de expressão plástica, ou desenho de criação". (COSTA, 2007:131). O "espírito5" contido nessa última frase, desenho de criação, corresponde ao sentido de desenho que abordamos aqui.

Cada projeto, a seu modo, inaugura um conceito próprio que, como composição, obedece a uma ordem exclusiva e única, por possuir uma condição constitutiva própria e independente de fatores externos. O desenho se apresenta como um caminho que consagra à obra uma identidade artística. A identidade é a qualidade que determina a essência da obra.

- Mas como um desenho revela ou quem sabe, desvela, essa intenção. Você pode demonstrar?

\section{- Sim. Parodiado Bluteau: Que catedrais tendes em pensamento?}

Debruço-me a seguir, nos desenhos de Oscar Niemeyer e Le Corbusier. Apresento o "confronto" entre as escolhas ou partido arquitetônico e busco demostrar como o desenho consubstancia as intenções artísticas de cada um desses arquitetos e, ainda, de como o desenho antecipa e testemunha a diferença de ideários entre eles.

\section{Niemeyer}

O ponto de partida é observar tão somente o desenho. 0 que ele revela como ideário, a partir de sua composição. Convido-te para esse exercício.

Observe o desenho da Catedral de Brasília (desenho 1) de Niemeyer.

Há simetria. Ela é determinante.

A representação está em corte e valoriza forma estrutural (caráter tectônico) coerente com o discurso de Niemeyer, que sempre defendeu que o momento de criação da Arquitetura se dá na medida em que a estrutura se define. Por outro lado, verifica-se a
3

s. f. 1. Disposição do espírito que induz a esperar que uma coisa. Se há-de de realizar ou suceder. 2. Expectativa. Coisa que se espera. Confiança.

4

Faculdade que tem o espírito de representar imagens; fantasia. 2. Faculdade de evocar imagens de objetos que já foram percebidos; imaginação reprodutora. 3.

Faculdade de formar imagens de objetos que não foram percebidos, ou de realizar novas combinações de imagens. 4. Faculdade de criar mediante a combinação de ideias. 5. A coisa imaginada. 6. Criação, invenção. 9. Liter. Arte. Invenção ou criação construtiva, organizada(por oposição a fantasia, invenção arbitrária).

5

A etimologia estrita do termo indica o produto de uma destilação: o espírito é o sopro (spiritus) Na filosofia helegiana o Espírito - que é a verdade na Natureza - é a princípio subjetivo (na consciência e nos fatos psíquico individuais); torna-se depois objetivo (na moral e no direito) e finalmente absoluto por intermédio da arte.

(DUROZOI, 2005: 163) 


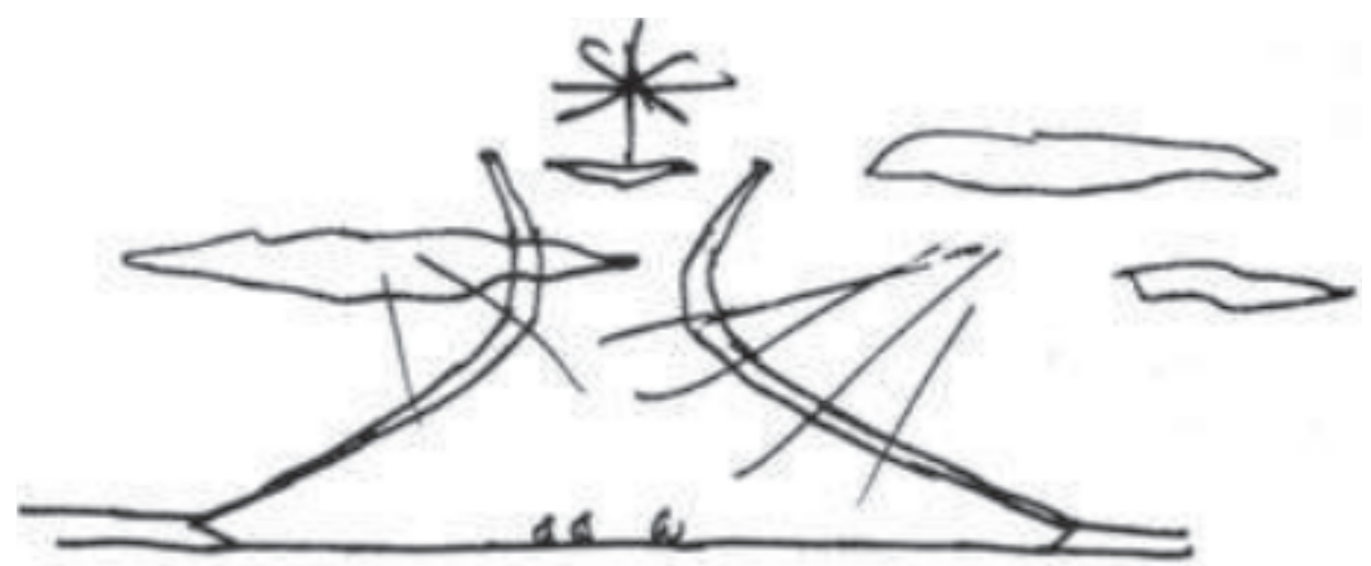

DESENHO 1: Desenho Catedral de Brasília. Oscar Niemeyer, 1950 - 1970.

Fonte: QUEIROZ, 2008.

presença da linha do horizonte. Além disso, o desenho de se define em um único plano, com a ausência da perspectiva.

As "paredes" são a própria estrutura e não tocam o solo.

Apesar da ausência da representação do entorno, Niemeyer representa os elementos da natureza, as nuvens. Uma delas está dentro e fora da catedral, assumindo um caráter alegórico e reforça, ainda, a presença dos raios solares sobre a representação da escala humana.

Observe o crucifixo. Ele comparece numa proporção de quase $1 / 3$ do desenho e, e ao mesmo tempo flutua na transição do edifício e a natureza. Além disso, compõe a simetria do edifício.

A Catedral em si tem uma base, entretanto esta não está fixada ou apoiada em nada. Reiterando a leveza do crucifixo.

A simetria sugere homologia entre as partes e é reforçada pela representação em corte, que aproxima o expectador, colocando mesmo tempo dentro e fora do espaço.

A linha do horizonte paralela à linha do piso promove a incorporação do infinito em continuidade com o espaço interno, ou seja, elimina a diferença de valores entre os espaços externos e internos.
Há continuidade entre o natural e o artificial pela presença da linha do horizonte que estabelece, ainda, uma relação entre espaço abstrato (linha do horizonte) e a concretude da forma arquitetônica.

\section{Le Corbusier}

Diametralmente oposta é a escolha que Le Corbusier ao apresentar o desenho da Igreja Saint-Pierre de Firminy (desenho 2). Essa igreja foi projetada para fazer parte do conjunto urbano de Firminy-Vert, prevista no primeiro plano urbanístico de 1954.

No desenho de Niemeyer, o horizonte é considerado uma manifestação fenomênica, diferente de Le Corbusier, cuja presença do horizonte é a própria essência, e que sintetiza a noção de natureza.

No desenho de Le Corbusier, há ausência da simetria, a representação se dá em perspectiva. O volume é determinante, prismático e não revela a relação do espaço interno com o externo. Tão pouco há distinção entre fechamentos e estrutura do edifício, ou seja, não a há valorização do caráter tectônico, e as aberturas são definidas com pequenos "rasgos" nas paredes.

O volume principal da igreja está centralizado na composição e na estrutura a paisagem. O crucifixo está vinculado ao volume principal, porém deslocado com dimensão muito inferior a esse volume.

O volume prismático estabelece um caráter simbólico que tradicionalmente legitima criações míticas, principalmente as representativas do sagrado. 


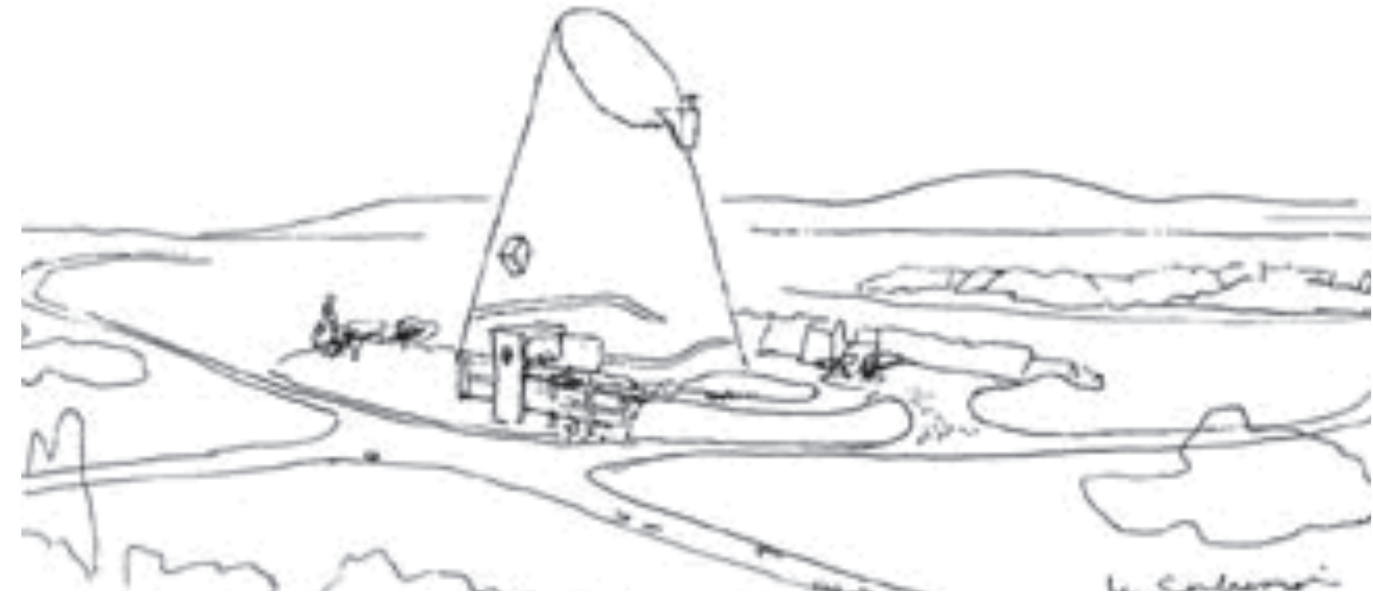

DESENHO2: Desenho original de Le Corbusier - primeiros estudos da Igreja 19 setembro de 1963. Fonte: fonte: http://lecorbusier.ville-firminy.fr/

A representação do objeto arquitetônico inserido na paisagem infere um modo de apropriação que depende do deslocamento, ou seja, infere a necessidade do percurso, induzindo o caráter da "peregrinação" - que o situa no mundo dos homens (o espaço profano ${ }^{6}$ ). O espaço interno (o espaço sagrado ${ }^{7}$ ) não se revela. Pequenos rasgos de luz iluminam esse espaço interno.

A "representação" do entorno natural é determinante, pois reforça que há dois momentos: uma paisagem externa ao edifício e o outro interno, o espaço dos "deuses".

\section{- A contraposição entre os desenhos das igrejas de Niemeyer e Le Corbusier demonstra que as escolhas desses arquitetos assumiram representações distintas. Você acredita que o modo de representar, ou apresentar, define o partido arquitetônico do projeto da Igreja.}

\section{- Não apenas acredito como tentarei demonstrar que se trata de uma escolha deliberada.}

Observe que o no desenho de Niemeyer ele subverte o significado da estrutura, conferindo leveza àquilo que, por princípio, suporta o peso. A beleza nasce nesse "jogo"; a forma plástica das colunas e a técnica estrutural constiuem uma unidade, constituem a própria Arquitetura e o desenho revela essa intenção:

A forma plástica evoluiu na Arquitetura em função das novas técnicas e dos novos materiais que lhe dão aspectos diferentes e inovadores. [...] "as formas livres e inesperadas que o concreto permite e os temas modernos solicitam." [...] Para alguns, é a função que conta; para outros, inclui a beleza, a fantasia, a surpresa Arquitetural que constitui, para mim, a própria Arquitetura. E essa preocupação de criar a beleza é, sem dúvida, uma das características mais evidentes do ser humano, em êxtase diante desse universo fascinante em que vive. E isso encontramos nas épocas mais remotas, com o nosso ancestral longínquo a pintar as paredes de sua caverna, antes mesmo de construir o seu pequeno abrigo. E o mesmo se repete pelos tempos afora, a partir das pirâmides do Egito. Arquitetura escultura. Forma solta e dominadora sob os espaços infinitos. (NIEMEYER, 2005:16-18)

Para Niemeyer (2005), a arquitetura se baseia em razões permanentes, em leis eternas de equilíbrio ${ }^{8}$, proporção $^{9}$ e harmonia e que se traduz na aproximação entre o espaço interno - a morada dos deuses (o sagrado) e o espaço externo - a morada dos homens (o profano). Seu desenho promove o espírito de leveza, estabelecendo a proximidade do "profano" (o homem) com o "sagrado" que se vincula a natureza (representada alegoricamente pelas nuvens e linha do horizonte), que separa o homem da terra (colocando abaixo da linha do horizonte) e une ao mesmo tempo ao "céu" (representado pelas nuvens que atravessam a catedral).
6

No pensamento de Bataille o mundo profano é delimitado pelas interdições graças as quais o homem adia a violência da natureza; por isso pode ser consagrado ao trabalho regular e deixa o campo livre para a extensão da racionalidade. (DUROZOI,2005:383)

\section{7}

Em oposição ao profano, o que se determina por sua separação do mundo comum: o sagrado é objeto tanto do fascínio quanto da rejeição. No sentido atenuado, sinônimo de respeitável, principalmente em moral. Evocam-se os direitos "sagrados" da pessoa humana.

8

Condição de um sistema em que as forças que sobre ele atuam se compensam, anulando-se mutuamente.

2. estado ou condição do que se mantém constante, inalterado; estabilidade; 3. distribuição, proporção harmoniosa; harmonia; 4. estabilidade mental e emocional; autocontrole, comedimento. 
Relação das partes de um todo entre si, ou entre cada uma delas

e o todo, quanto a tamanho, quantidade ou grau; razão;

2relação entre as partes de um todo que provoca um sentimento estético de equilíbrio, de

harmonia; 3justa relação entre coisas; conformidade de equilíbrio, de harmonia.

Projeto é um plano para a realização. designnio, intenção ou esboço. Esta é uma palavra oriunda do termo em

latim projectum que significa "algo lançado à frente".

Subjetividade é entendida como o espaço intimo do indivíduo, ou seja, como ele "instala" a sua opinião ao que é dito (mundo interno) com o qual ele se relaciona com o mundo social

(mundo externo), resultando tanto em marcas singulares na formação do indivíduo quanto na construção de crenças e valores compartilhados na dimensão

cultural que vão constituir a experiência histórica e coletiva.
O desenho de Corbusier revela outra intenção. Ele também subverte o aspecto estrutural, destacando o volume como objeto único de forma "pura"e primática e em suas palavras, "um pensamento que se ilumina sem palavras nem sons, [...] unicamente com prismas que mantêm relações entre si” (LE CORBUSIER, apud KATINSKY, 2007:1)

Seu desenho engendra o espírito de sutileza. Relação de confronto entre o "sagrado e profano". No desenho de Le Corbusier, a sutileza se dá no confronto entre o externo e o interno - relação de distanciamento entre o "profano e o sagrado" -, vínculo com a consciência. Suas palavras descrevem esse sentido: "Aproxima-se, vê-se, fica-se interessado, pára-se, aprecia-se, gira-se em torno, descobre-se. Recebe-se continuamente comoções diversas, sucessivas. E o jogo jogado aflora [...] em consequência, o jogo jogado não se estabeleceu sobre um ponto de vista central, ideal rotativo e com visão circular simultânea". (CORBUSIER. 1998:61)

Revela-se a necessidade do percurso (peregrinação) que se caracteriza pela representação em perspectiva - a promenade arquitetural e que valoriza o percurso como uma estratégia conceitual de fruição da relação objeto arquitetônico "versus" natureza. Os caminhos e passagens devem ser diversos. A "paisagem" é fundamental para reforçar o desenho da catedral; o dentro e o fora.

Isso posto, desenho e projeto ${ }^{10}$ (humano) coincidem.

Os desenhos de Niemeyer e de Le Corbusier revelam caminhos distintos para um mesmo fim: valorizar a presença do homem como princípio. Eles compartilham o mesmo ideário moderno que engendra a subjetividade ${ }^{11}$.

O caminho de Niemeyer nos instiga pela da imaginação, motivado pela emoção e pela afinidade com a natureza. O desenho de Le Corbusier, nos motiva pela vontade e instiga nossa consciência, ou seja, consciência de si e de nossa relação com o mundo.

Busquei demonstrar pelo desenho do arquiteto a relação entre o projeto e uma intenção; que desenha para o futuro, aquilo que sonha realizar. $\mathrm{O}$ arquiteto que desenha com o objetivo de atender apenas as finalidades práticas da arquitetura abandona seu sonho, perde a esperança de fazer algo que possa efetivamente contribuir para um mundo melhor.

\section{- Significa dizer que o arquiteto é um artista?}

$-\operatorname{Sim}$.

Defender a formação artística do arquiteto não significa desconsiderar as demais áreas de conhecimento, mas resgatar o mesmo sentido poético que Alberti confere à citada tríade vitruviana firmitas, utilitas et venustas, no sentido de que cada uma dessas partes deve ser adequada à respectiva destinação, na perspectiva de uma sanidade total. Em outro ponto de vista, para sua firmeza e duração, essa tríade não pode apresentar defeito, deve ser sólida, quase eterna. E quanto à beleza, seja elegante, harmonizando e embelezando os pormenores.

A respeito da arte e da praxis humana, Hanna Arendt afirma:

O mundo de coisas feito pelo homem, o artifício humano feito pelo homo faber, só se torna uma morada para os mortais, um lar cuja estabilidade suportará e sobreviverá ao movimento continuamente mutável de suas vidas e ações, na medida em que transcende a mera funcionalidade das coisas produzidas para o consumo e a mera utilidade dos objetos produzidos para o uso. (ARENDT, 2008:186, 187).

Trata-se da qualificação estética do desenho na arquitetura, sobre o significado do desenho como dimensão artística, nos termos que propõe Artigas (1999) que relaciona o ensino, a técnica e a arte:

[...] Creio que das considerações que fiz
até agora já é possível concluir que
ideário nos tem impedido de enfrentar o
ensino racional, cuidadoso e
interessado do desenho nas escolas
brasileiras. Para desenhar é preciso ter
talento, ter imaginação, ter vocação.
Nada mais falso. Desenho é linguagem
também e enquanto linguagem é
acessível a todos. Ademais, em cada
homem há o germe, quando nada, do
criador que todos os homens juntos
constituem. E como já tive oportunidade
de sugerir antes, a arte, e com ela uma
de suas linguagens - o desenho -,é
também uma forma de conhecimento.
(ARTIGAS, 1999:77)

Sobre a técnica: 
[...] Para nós, arquitetos, a televisão e o rádio, que informam com a velocidade da luz, sugerem novos conceitos de espaço. O espaço como que se torna transparente e o homem ubíquo. Novas simetrias são possíveis. Enriquece o cabedal de matéria para organizar novos desenhos e novos projetos. Em lugar de uma máquina todo-poderosa que traça o nosso destino e determina os nossos desígnios, que assume nossa linguagem e, portanto desenha e projeta sem o controle de nossa mente, o que se passa é o contrário. É melhor e mais perfeita a ferramenta - melhores nos sairão as obras. Um desenvolvimento cada vez maior e tanto melhor quanto excessivo. (ARTIGAS, 1999: 79)

Sobre a arte:

[...] O conflito entre a técnica e a arte prevalece ainda hoje. Ele desaparecerá na medida em que a arte for reconhecida como linguagem dos desígnios do homem. A consciência humana, com seu lado sensível e seu lado racional, não tem sido convenientemente interpretada como um inteiro, mas como a soma de duas metades. Aos artistas, principalmente, compete conhecer esta dicotomia para ultrapassá-la. Com certeza, a semântica da palavra desenho tende a enriquecer nessa direção. Sentimos já as primeiras mudanças. $O$ desenho não é a única linguagem para o artista. E as linguagens são formas de comunicação ligadas estreitamente ao que exprimem. (ARTIGAS, 1999:80)

A escolha é a essência do desenho na Arquitetura. Compete às escolas de Arquitetura formar arquitetos conscientes de suas escolhas e responsáveis por seus desenhos. Essa perspectiva norteia o compromisso com a formação acadêmica dos futuros profissionais da Arquitetura, com a promessa na construção de um mundo melhor.

Se por um lado desenho é traço, risco, por outro ele é intenção, desígnio. Daí uma homologia entre o significado das palavras desenho, projeto e risco. Ambas possuem um duplo sentido. Desenhar é arriscar-se, expor-se.

\section{Referências}

ABBAGNANO, Nicolas. Dicionário de Filosofia. $4^{\circ} \mathrm{ed}$. São Paulo: Ed. Martins Fontes, 2000

ALBERT, Leon Battista. Da Arte de Construir - Tratado de Arquitetura. Ed. HEDRA. 2012.

ARENDT, Hannah. A condição humana. São Paulo: Forense Universitária, 2008.

ARTIGAS, João Batista Vilanova. Caminhos da arquitetura. São Paulo: Cosac e Naify, 1999.

CORBUSIER, L. Por uma Arquitetura. $5^{\circ}$ edição. Tradução de Ubirajara Rebouças. São Paulo: Ed. Perspectiva, 1998.

COSTA, Lucio. Sobre arquitetura. Porto Alegre: Imprensa Universitária. Centro dos Estudantes Universitários de Arquitetura. 1961-1962

. Arquitetura. Rio de Janeiro: José Olympio,

2002.

. Arquitetura. Biblioteca Educação é Cultura, Rio de Janeiro, Bloch/FENAME, 1980. $10 \mathrm{v}$.

Sobre Arquitetura. Porto Alegre: Uniritter, 2007.

. Considerações sobre arte contemporânea (1940). In: Lúcio Costa, Registro de uma vivência. São Paulo: Empresa das Artes, 1995.

. O ensino do desenho. Revista Cultura. n.1. 1948. Arquitetura brasileira Col. Cadernos de Cultura, n II. Autor: Lúcio Costa. Fonte: [me] Ministério da Educação - Domínio Publico.

COSTA, Maria Elisa (Org.). Com a palavra, Lucio Costa. Rio de Janeiro: Aeroplano, 2000.

GOROVITZ, Matheus. Brasília, uma questão de escala. São Paulo: Projeto, 1985.

. City and Citizenship: a contribution to the study of the modern city considered a work of art Chandigarh and Brasilia. On Line International. Disponível em: <http://www.archiport.it/gorovi> 2005. Acesso em: 5 mai 2009.

Da educação do juízo de gosto R. Bras. Est. 
Pedag. Brasília, ano 79, n. 93, p. 86-94, set./dez. 1998

Sobre a qualificação estética do objeto, ou da graça e da dignidade. Projeto. São Paulo, n. 280, p. 20-22, 2003.

Os riscos da modernidade. Projeto.São Paulo, n. 264, p. 22-25, 2002.

. A arquitetura brasileira avançou, apesar das dificuldades impostas pela globalização. Projeto. São Paulo, n. 251, p. 46-46, 2001.

Sobre a obra de arte. Cadernos Eletrônicos da FAU Unb, Disponível em: <http://www.unb.br/fau/pos_grad>2000. Acesso em: 5 mai 2009

Da educação do juízo de gosto. Revista Brasileira de Estudos Pedagógicos, Brasília, v. 79, n. 193, 1999.

La arquitectura de Niemeyer en Brasilia. In: VILLAESCUSA, Eduard Rodriguez; FIGUEIRA, Cibele Vieira (Org.). Brasilia 1956 - 2006 de la fundación de una ciudad capital, al capital de la ciudad. Barcelona: Milenio, 2006, v. 1, p. 25-51.

Sobre ojogo de escalas em Brasília. In: RIBAS, Otto. (Org.) Visões de Brasília. Brasília: IAB-DF, 2005, v. 1

Cidade e cidadania. In: QUETGLAS. Josep (Org.) Massília, 2003. Barcelona: Fundación Caja de Arquitetos, 2003, v. 1, p. 178-189.
Os riscos da modernidade O Campus da Universidade do Brasil. In: QUETGLAS, Josep (Org.). Massilia, 2002. Anuario de estudios Lecorbusieranos. Barcelona: Fundación Caja de Arquitectos, 2002, v. 1, p. 134-140.

Desenho e soberania da educação do juízo de gosto. In: GOUVÊA, Luiz Alberto de Campos et al. (Org.). Contribuição ao ensino de arquitetura. Brasilia: Instituto Nacional de Estudos e Pesquisas Educacionais, 1999, v. 1, p. 35-48.A

KANT, Immanuel. Crítica da faculdade do juízo. Rio de Janeiro: Forense Universitária, 2005.

KANT, Emmanuel. Crítica da razão pura. Rio de janeiro: Tecnoprint, s/d

KATINSKY, Julio R. Técnica e arte na obra de Oscar Niemeyer. Disponbível em: <http://www.revistaau.com.br/arquiteturaurbanismo/165/artigo67580-2.asp > 2007. Acesso em: 25 jun 2009.

KATINSKY, Julio R. Renascença estudos periféricos. São Paulo: FAUUSP, 2003.

QUEIROZ, Rodrigo (Org.) Coleção Niemeyer. Desenhos originais de Oscar Niemeyer. MAC/USP, São Paulo, 2008

ZUCCARO, Frederico. Idéia dos pintores, ecultorese arquitetos. In: ib. id., Vol. 1. A idéia e as partes da pintura. 